\title{
Service-learning - Diagnostic technologies presented by Ph.D. students to help socially neglected people during the SARS-CoV-2 pandemic
}

\author{
José S. Torrecilla ${ }^{1}$, John C. Cancilla ${ }^{2}$, Sandra Pradana López ${ }^{1}$, Ana M. Pérez Calabuig ${ }^{1}$, \\ Manuel Izquierdo ${ }^{1}$, Yolanda García Rodríguez ${ }^{3}$, Edgar Antonio Reyes Ramirez ${ }^{4}$, \\ Kelvin de Jesus Beleño Saez \\ ${ }^{1}$ Dpto. Ingeniería Química y de Materiales. Universidad Complutense de Madrid, Spain, \\ ${ }^{2}$ Scintillon Institute, USA, ${ }^{3}$ Dpto. Psicología Social, del Trabajo y Diferencial. Universidad \\ Complutense de Madrid, Spain, ${ }^{4}$ Elevadores Schindler México, Mexico, ${ }^{5}$ Dpto. Ingenieria \\ Mecatrónica. Universidad Autónoma del Caribe, Colombia.
}

\begin{abstract}
Innovation is becoming a fundamental part of many sectors and environments, including universities, not only regarding their research but also how education is approached. In this line, one of the ways to achieve these objectives is based on a collaboration between society, which presents a need to be solved, and the University. This society-university integration is achievable via the Service-Learning methodology (SLM), which has always been based on establishing strong links between the educational world and society.

This paper presents a SLM-based project linked to technological development for the health sector during the SARS-CoV-2 pandemic. Specifically, undergraduate chemistry students, and Ph.D. students led by professors have presented part of their technological developments to people in society who are at risk of exclusion to help them understand aspects of infection as well as diagnosis of diseases. In short, the objective is to transfer in an enjoyable fashion, a set of technological developments and knowledge that can help society understand aspects related to the COVID-19 pandemic.
\end{abstract}

Keywords: Service-learning; teaching; social integration; pandemic. 


\section{Introduction}

Year 2020 has been a period of learning and development for many sectors of society. The SARS-CoV-2 pandemic has forced both society and the university itself to go through a challenging time in almost all aspects. These social circumstances are serving to frame the training procedures of our future professionals (Martinez et al., 2003). Undoubtedly, everything that is being experienced in society should help mold the training channel for students, in order to properly manage and employ current resources, especially in the most underprivileged social strata.

An adequate understanding between university teaching and society makes it possible to address social shortcomings and educational considerations. This bond must be integrated within an educational proposal that combines learning and community service in a single plan. This plan is called the service-learning methodology (SLM), which is founded on an experience-based methodology, in which students (guided by professors) are engaged in helping the community and, at the same time, achieving their sought professional competencies (Annete, 2000; Gallego, 2014).

Some authors describe SLM as a solidary activity of students, oriented to effectively meet the needs of society and in line with the curricular contents of their educational programs (Tapia, 2008). SLM is an innovative approach that brings together the learning of contents, competencies, and values with the development of tasks of service to society (Tinkler, 2019). In this way, learning extends outside the classroom and the student learns the importance of their presence and skills for communities in the field of service. This methodology presents effective aspects in different areas of the student's training within the university: (i) the fact that the SLM focuses on a more practical and applied training results in an improvement of the academic curriculum; (ii) training in values which are useful for the future of the students while reflecting on society and its communities; (iii) link with the community since the activities linked to the SLM respond to a professional intervention on a real social problem (Gallego, 2014). Activities linked to SLM group training aspects based on the combination of theory with practice, the classroom with real problems, or student's training with social commitment (Butin, 2006; Manzano, 2010). That is why a quality university education cannot separate professional dvelopment from social training (Martinez, 2007; Gallego, 2014). So much so, that in recent years many universities are actively implementing methodologies based on SLM in a large part of the degrees they offer. This has led to the implementation of different institutional programs. For example, "Lernen durch Engagement", in Germany, where voluntary internships are being replaced by SLM activities. Likewise, networks are being developed to facilitate the joint development of this type of activities (Gallego, 2014). In view of this application, the implementation of the SLMbased methodology is a great improvement in the pedagogical field for the university setting 
(Dillabaugh, 2019; Sewry, 2018). In relation to this setting, it is not only focused on undergraduate students, but also on Master's and Ph.D. students.

In previous work, this methodology is also being transferred to the field of training future Ph.D.s (Torrecilla et al., 2020). In particular, it is valuable that the research and technological development carried out in the laboratories of the universities, as well as the new generated knowledge, becomes known by society (Sewry, 2018; Saitta et al., 2011). Communication promotes the generation of more knowledge as society itself reveals its main needs (Ching, 2018). The application of this methodology in university doctoral studies fosters solidarity and the integration of different communities, stimulating the much needed mutual appreciation.

The objective of this work is to employ the SLM methodology during the training of graduate students. For this purpose, aspects related to the development of technological applications based on artificial intelligence in the field of disease diagnosis will be addressed. These technologies will be disseminated as a priority in neglected communities. The activities are developed for people at risk of social exclusion who meet in centers belonging to the Madrid City Council. More specifically, in different centers belonging to the Department of Social Inclusion for Community Integration and Social Emergency of the Madrid City Council (Spain). For this purpose, the results of research projects linked to the diagnosis of diseases being developed by doctoral students supervised by the faculty will be used. The main objective pursued is the integration of society-university and, to this end, it is worth highlighting: (i) to make society aware of the main results obtained in the aforementioned field; (ii) to make it easier for society to participate in each of the steps and feel sufficiently integrated to contribute ideas, needs, and possible lines of improvement; (iii) to transmit the innovation criteria to society and for society itself to provide feedback; (iv) for students to receive the values transmitted directly by the communities themselves at risk of exclusion; and (v) for the service to become a workshop of values and knowledge.

\section{Applied Service-Learning Methodology}

This manuscript presents a SLM-based approach developed within the Ph.D. studies in the Chemical Engineering program of the Chemistry Division of the Complutense University of Madrid (UCM) (Spain). This project takes place during the academic years 2019-20 and 2020-21. This development focuses on the design of a plan to integrate SLM activities in the training of $\mathrm{Ph}$.D. students. The team consists of two university professors and four graduate students. In addition to the values that the students will receive, this project will significantly improve their ability to present ideas. Within the development stages of the SLM project presented, six phases are contemplated, which will be carried out sequentially (Gallego, 2014). 
a) Analysis of resources and situation: in this first phase, the available human resources, the situation, and the specific problems of the community to which the project is addressed will be evaluated.

b) Initial preparation: in this stage, a list of activities to be developed by SLM teachers and students is designed. This scheduling was supervised by the Madrid City Council linked to this project.

c) Coordination of tasks: different coordination meetings are held in which each of the graduate students and faculty organized their schedules and times to fulfil the tasks to be developed in the project.

d) Carrying out activities: two activities are carried out for different communities and different videos made for their diffusion in each of the communities. The activities started with workshops entitled "Breath, a New Approach to Prevention" (May 14, 2019) and "Robotics, a New Way to Help Society" (February 26'2020), Figure 1. Later, videos were developed to disseminate the results for the same communities mentioned above. The tasks being developed are contemplated in two teaching innovation projects; "Service-Learning in the Transfer of Technological Results", and "Service-Learning, a Way to Transfer to Society the Technological Results of the University", funded by UCM. Likewise, after each event, meetings will be held with all the parties involved in the project to learn about relevant aspects and improve its quality.
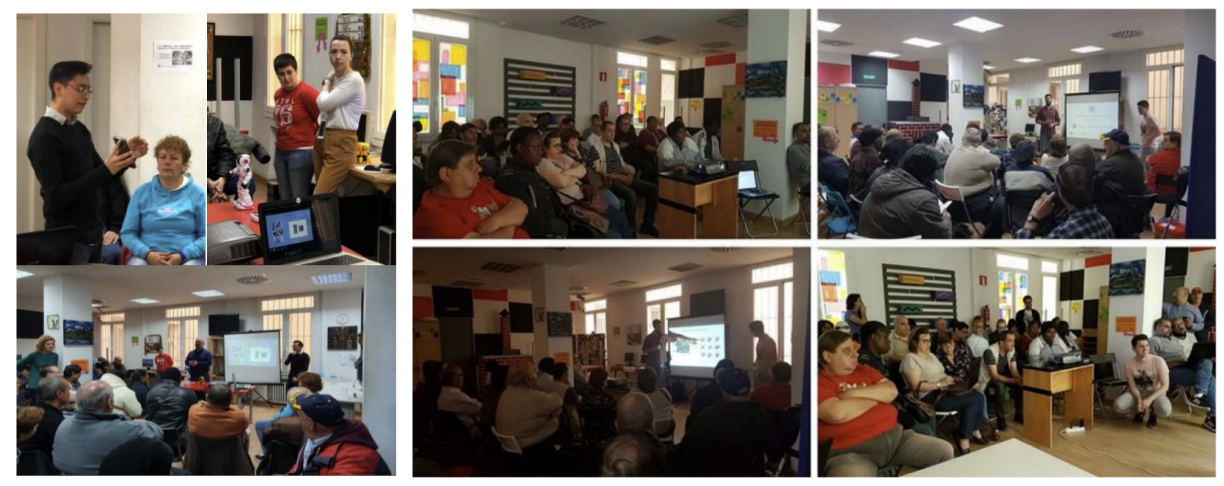

Figure 1. Images taken at the workshops entitled "Robotics, a New Way to Help Society" (left) and "Breath, a New Approach to Prevention" (right).

e) Reflection: the information gathered in each activity will be used to improve and facilitate the search and design of future events for SLM students. 


\section{Results}

Currently, given the problems that still exist derived from COVID-19, there are still some online events to be held to finalize the results shown in this project. Even so, the results are representative nonetheless. The processing system of the surveys has been organized from the transcription of the recorded texts, identifying complete sets. The content analysis was carried out with Statgraphics 18. The analysis was informative, so the task of categorizing and coding the information collected was carried out. For the validation of the category system, the two professors linked to the project being developed and also a group of two more professors not initially linked to the project were involved. The kappa index was calculated to reflect inter-observer agreement. This coefficient, in all cases, has exceeded the value of 0.70 (Gallego et al., 2014). The results have been elaborated through surveys to both students and teachers at two levels, taking into account students and teachers.

At the student level, the study was conducted in the three areas of student training during the development of the SLM methodology, specifically: (i) academic demands, where the mastery of contents, positive attitudes towards work, knowing presentation options, and recognizing realistic ideas in the world of work among others will be considered; (ii) the characteristics implicit in the development of values, including aspects such as self-esteem, empathy, teamwork, self-improvement, motivation, creativity, communication, responsibility, and more; (iii) relevant aspects in the area of community relations will be considered, such as social development, community intervention, diversity and values, coexistence and interaction, among others.

Among the results of the interviews, the importance of problem solving by doctoral students directly from the students stands out. Solving real problems through the union of different areas of knowledge not only linked to the research presented was adopted by the students. Another feature that most surprised the members of the project is the possibility of defending their developments in other non-technical forums as well as the received questions. In practice, the return to work in the laboratory made them see their tasks and objectives from other points of view, considering the advantages of the application of what they are doing. In general, one of the most common results is the pleasure of helping people who are suffering situations that are very different and complicated from those of the doctoral students. Also, in general, it was very interesting to see how science and technology can entertain other people, even when their background is not technical.

At the level of teachers, the categories that were addressed are distributed in the same areas considered in the previous level, specifically (i) in the area of academic curriculum, the articulation of contents, quality of learning, didactic strategies, active participation, among others, will be considered; (ii) analysis of the implicit characteristics of training in values, including aspects such as teamwork, motivation, leadership, responsibility, empathy, among 
other aspects; (iii) linking with the communities to aid in social development where diversity and values, pro-socialization, community intervention, among others, will be taken into account. In general, the professors who have participated in this project consider this methodology very promising to present to researchers a new scenario in which to promote and share their technological developments. In addition, it complements one of the aspects that gives great importance to the development of research projects related to the influence on society of the results obtained.

\section{Conclusions}

This manuscript presents the preliminary results of several projects based on the service learning methodology (SLM). Through these projects, centers with a population at risk of exclusion are integrated with doctoral students using the SLM methodology. Although the project will continue in the coming months, the results are promising, both on the part of the doctoral students and professors as well as the people belonging to communities at risk of exclusion.

The doctoral students have acquired competencies and social skills in terms of collaboration with the community, and at the same time they have strengthened ties with people with serious social problems. This synergy has greatly favored not only knowledge but also training in values and community service. So much so that the compelling results that have been obtained are opening up the possibility of establishing new activities of the technological projects that are launched in the Algoreach research group.

\section{Acknowledgements}

This work has been carried out with the financial support of the SL UCM 2018/19_16 and SL UCM 2019/21_14 project and the Madrid City Council.

\section{References}

Annette, J. Civic participation and education for citizenship. Political Studies Association, UK, 50th Annual Conference, London, 2000.

Butin, D.W. (2006). The limits of service-learning in higher education. The review of Higher Education, 29: 473-498.

Ching, S.H. (2018). Turning a Service-Learning Experience into a Model of Student Engagement: The Lighthouse Heritage Research Connections (LHRC) Project in Hong Kong. Journal of Academic Librarianship, 44(2), 196-206.

Dillabaugh, J. (2019). Liberating Service Learning and the Rest of Higher Education Civic Engagement. Journal of Experiential Education, 42(1), 93-94.

Manzano, V. El modelo de Aprendizaje Servicio y su potencial para la educación superior. 
VI Jornadas de docencia en Psicología. Universidad de Sevilla, 2010.

Martínez, M. (2007). Formación para la ciudadanía y educación social. Revista iberoamericana de Educación $42,5$.

Rodriguez Gallego M. R. (2014). El aprendizaje-servicio como estrategia metodológica en la universidad. Revista Complutense de Educación, 25: 95-113.

Saitta, E.K.H., Bowdon, M.A., Geiger, C.L. (2011). Incorporating Service-Learning, Technology, and Research Supportive Teaching Techniques into the University Chemistry Classroom. Journal of Science Education and Technology, 20(6), 790-795.

Sewry, J.D., Paphitis, S.A. (2018). Meeting important educational goals for chemistry through service-learning. Chemistry Education Research and Practice, 2018, 19(3), 973982.

Tapia, M. Aprendizaje y servicio solidario. Buenos aires: Ciudad nueva, 2008

Tinkler, A., Tinkler, B., Reyes, C., Elkin, S. (2019). Critical Service-Learning: Learning Through Experience to Advance Teacher Education. Journal of Experiential Education, 42(1), 65-78.

Torrecilla, J.S., Cancilla, J.C., \& Lopez-Martin E. (2020) Service-Learning at the Postgraduate Level to Reach Depressed Sectors of Society. Higher Education Theory and Practice 20(9), 54-59. 